\title{
Does Branding Need Web Usability? A Value-Oriented Empirical Study
}

\author{
Davide Bolchini ${ }^{1}$, Franca Garzotto ${ }^{2}$, and Fabio Sorce ${ }^{2}$ \\ ${ }^{1}$ Indiana University, School of Informatics (IUPUI) - 535 W. Michigan St. \\ Indianapolis, IN 46202-3103 (U.S.A.) \\ dbolchin@iupui.edu \\ ${ }^{2}$ HOC Lab - Department of Electronics and Information, Politecnico di Milano \\ Via Ponzio 34/5, 20133 Milano (Italy) \\ \{franca.garzotto, fabio.sorce\} apolimi.it
}

\begin{abstract}
Does usability of a web-based communication artifact affect brand, i.e., the set of beliefs, emotions, attitudes, or qualities that people mentally associate to the entity behind that artifact? Intuitively, the answer is "yes": usability is a fundamental aspect of the quality of the experience with a website, and a "good" experience with a "product" or its reifications tends to translate into "good" brand perception. To date, however, the existence of a connection between web usability and brand perception is shown through anecdotic arguments, and is not supported by published systematic research. This paper discusses a study that empirically investigates this correlation in a more rigorous, analytical, and replicable way. Our main contribution is twofold: on the one hand, we provide empirical evidence to the heuristic principle that web usability influences branding, and we do that through four between subjects controlled experiments that involved 120 subjects. On the other hand, we inform the study with a systematic value-oriented approach to the user experience, and thus provide a conceptual framework that can be reused in other experimental settings, either for replicating our study, or for designing similar studies focusing on the correlation of web branding vs. design factors other than usability.
\end{abstract}

Keywords: brand, usability, value-centered approach, web application, communication goal, empirical study, inspection.

\section{Introduction}

For companies, educational or cultural institutions, charities, governmental bodies, politicians, artists, and many other subjects, the web has become one of main channels not only to inform and offer services, but also to build a relationship with stakeholders, and influence their attitudes and behavior [30][35]. In other words, the web is more and more a component of an ubiquitous and pervasive network of communication, interaction and information that aims at influencing the minds of people and ultimately, creating or strengthening a brand in the global society.

It is well known in brand design that a "good" direct experience with a "product" or one of its reifications translates to a "good" brand perception [18][34][37][41]. 
Since usability is a fundamental aspect of the quality of the experience with a website [1][2][29], we may well accept the thesis that usability somehow affects brand perception. Still, the existence of such correlation is usually discussed through anecdotic evidence, intuition, common sense, or design experience [16][23][28][38][26], but lacks support by publicly available systematic research.

In the context of a wider research action aimed at understanding the role of branding in the web design process [3][4][43], this paper attempts to investigate the relationship between brand perception and web usability in a more rigorous way. We present a study that involved 120 participants and was designed as four controlled between subjects experiments, each one considering a different website of a large company or institution, and its modified version in which we altered the usability for better or for worse. Our results show a statistically significant difference in brand perception when users are exposed to websites sharing contents and functionality but having different degrees of usability, thus providing some empirical evidence that usability does affect the strengthening (or weakening) of brands.

Our work also offers a novel contribution from a methodological perspective, and this consists of:

(a) adopting a structured value-oriented evaluation approach for operationalizing and measuring brand from a user-experience perspective (i.e., not from a marketing or economical perspective [17][42][36][31]);

(b) defining a conceptual evaluation framework that can be reused in other experimental settings, either for replicating our study or for designing similar studies focusing on the correlation of web branding $v s$. design factors other than traditional usability (e.g., related to aesthetics or attractiveness [9][10][21]22][24][25][27][32]).

The rest of the paper is organized as follows. After a survey of the related state of the art, we introduce the general evaluation approach and describe in details our empirical study. A discussion of our findings and some general lessons learned concludes the paper.

\section{Background and Related Work}

The notions of brand and its many declinations (e.g., branding and brand experience) are quite broad, and are defined in many different ways in the current literature on design, marketing, and advertising [16][18][31][36][41][42]. For the purpose of this paper, branding is the intentional process aimed at creating or promoting a brand, while brand defines the core messages designed around "who we are", "what we believe", "why you should trust us". The term brand refers therefore to the expected cognitive and emotional associations that people make with an "entity" (being it a product, a service, a company, an institution, a person or, at a broader level, a country or a culture). We can also say that a brand is a promise of values [41] that the entity can keep to all its stakeholders - customers, trades, stockholders, employees, fans, or supporters. As a person gets in touch with or lives by any concrete reification of a brand, a brand experience takes place. It consists of all the perceivable elements (communication artifacts, physical products, people, services, or events) that give to the customer the experiential, comprehensive feeling of the brand. A brand experience is what creates not only a functional, but also an emotional relationship with a product or service and the brand underneath it [26][28]. 
A number of studies pinpoint that when individuals have an active or interactive experience with a brand reification, e.g., shopping in a branded store, buying a service or searching for information in a branded web site, this has a greater affect on brand perception than an indirect, passive exposition to the brand such as in traditional advertising, because people tend to assign more weight to emotions emerging directly from their proactive experience [34][17][32].

Based on this general idea, several authors suggest that the quality of a web experience affects users' brand perception [2][16][18]. In particular, usability is held to play an importance in positively or negatively influencing the user's attitude towards the entity behind the website, as it is a fundamental factor in determining the quality of the user experience [2][16]. This principle is also illustrated in online articles and practitioner's guidelines by J. Spool [37][38], whose usability studies claim to show that a more successful user experience is created when website help users achieve their goals, which in turn translates into an improved brand perception. This study, however, like others often quoted in the practitioners' design literature, seems to be proprietary knowledge, whose data, methods and instruments are not widely shared with the research community. Little o no data are published on this topic. In most of the works that have examined how to design to maximize the effectiveness of online brand communication, and how usability may facilitate or hinder this process, arguments are at most anecdotic, and show little or no empirical data or systematic experiments.

Interestingly, one of the few published data sets on usability vs. branding, empirically shows an influence in the opposite direction, i.e., brand perception affects the perceived usability, and experimentally illustrates that (in mobile applications) the users' affection to a brand accounts for an improved level of perceived usability, despite the absence of significant differences in task performance [33].

Some empirical work explores the correlation between web usability and other quality factors of the user experience. The study reported in [9], for example, investigates the relationships between content, presentation, usability and memory, and their relative importance to the user's preferences. Moreover, attractiveness and aesthetic design are key factors in persuasive computing [13]. A number of studies have shown correlations between the perceived aesthetic quality of a system's user interface and overall user satisfaction [22][24][25][27], leading to claims that aesthetic design can have a stronger influence on users' attitude towards the system than traditional usability [39][40]. As to vertical domains, there are studies that examined the design factors that affect consumer's trust in e-commerce websites [15][38], or influence people's perception of the website credibility [11][12].

None of these studies explicitly investigated the effects of usability on the users' perception of the entity behind the web system, thus they do not consider brand perception. Still, most of the above mentioned works have an important role in the research area of branding in relationship to user experience design, and in particular can pave the ground to theoretically framing the results of our study from a wider perspective.

Methodologically, the study presented in this paper systematically adopts a value-oriented approach, and is the logical follow-up of our previous works in web branding, communication requirements analysis and evaluation [3][4] [43]. In [3], we introduced the concept of communication goals for web applications, framed it in the 
context of goal-based requirements engineering, and modelled its impact on the various design dimensions. We have started systematically addressing the problem of elaborating requirements to inform how brand values are communicated through design. Then, thanks to extensive project experience and work with design teams, this initial study led to a refinement of our approach, reported in [4][43], pinpointing more precisely the relationships between communication requirements, branding, and design aspects.

All the above mentioned methodological results are centered around the concept of "value" - a notion that has been investigated in different communities including HCI, e-commerce, design, requirements engineering, and web engineering. ValuesSensitive Design [14], for example, stresses the importance of embedding value-aware requirements throughout any technology development, particularly emphasizing values with moral significance. Value-Centered Design [7][8] generalizes the notion of value by extending it to whatever a person finds worthwhile. In web engineering, Value Based Design (VBD) [19] provides a more pragmatic and systematic approach with respect to HCI design works, looking at the notion of "value as worth" from a strictly business perspective, in terms of the economic benefit that is induced by a web system.

For the purpose of the research reported in this paper, the notion of value is regarded not only as a driver for requirements and design of branded web applications, but it also provides the key to operationalize and measure brand perception into more precise and analytical elements, as explained in the next section.

\section{Experimental Design}

\subsection{Scope}

The scope of our research action are content intensive branded web sites, i.e., web applications that provide a large quantity of articulate content and services and at the same time need to sustain or to create a positive brand image. We purposefully do not address web sites that are mainly a marketing tool, and, like wall paper street advertisement or TV commercials, are almost exclusively designed to convey brand messages. These are typically websites with little or no informative content, but a lot of animations, gaming activities, or streaming media (videos): their main goal is not to inform and provide services, but to attract user's attention and provoke emotions.

Measuring brand in relationship with usability requires operationalizing the concepts of usability and brand.

For the precise scope of our study, we are interested to the "classical", functional view of web usability, which considers the operational ease of use and the degree of effective and efficient support to users' information and operational goals, according to the known ISO-9241 definition. We well acknowledge that current research explores aspects of the quality of experience (e.g. aesthetics, attractiveness, engagement, and affective dimensions) that goes much beyond a traditional notion of usability [10][1][29][32]. Still, the impact of these user experience dimensions on brand is outside the scope of this paper, although the methodological elements we 
propose provide a conceptual framework that can be also adopted for research on this issue.

It is well known in HCI how to measure "traditional" usability. In contrast, how to translate the general and vague concept of brand into lower level measurable factors from a user-experience perspective (i.e., not from perspective of the economic value of a brand) is still a largely unexplored issue.

As we define brand as a promise of values, we conceptualize brand in terms of Brand Values. A brand value can be a moral, ethical, social, or cultural belief which an entity is committed to, or a quality of the entity that is worthwhile for people, either at individual or collective level. This quality is not necessarily functional, but can be something that gives rise to positive, emotional or affective, effects. Brand values represents therefore those traits of an entity's personality that the entity holds as salient to communicate to its target via the its products or communication artifacts (e.g., its web site) and that are expected to be perceived by the users. We then measure brand in terms of Brand Values Perception, i.e., the degree of people's conscious awareness of and trust on the values promised by the entity or institution associated to the brand.

\subsection{Hypothesis and Study Variables}

In order to investigate the effect of usability on brand, we need to study whether the exposure to web sites having different levels of usability determine a variation of the users' perception of brand values.

The study was designed as four between subjects controlled experiments (each one involving a different website), in which the independent variable is the usability of a website, manually manipulated with focused design interventions, and the dependent variable is the difference in brand value perception induced by the use of the web site.

In a nutshell (see Figure 1), the experimental design was set up in such a way to create, for each different web site, two experimental conditions: the original web site and a modified web site where we intervened on the design by improving or worsening the measured degree of usability, without altering content and functionality. Participants were randomly assigned to an experimental condition, and brand values perception in each group was assessed before and after a supervised use to the system.

The underlying hypothesis of the study is that there is a statistically significant difference in the variation of brand values perception induced by the exposure to the two different experimental conditions (an original web site and its version with modified level of usability). This hypothesis can be formalized as follows:

$$
\begin{gathered}
U(\mathrm{~W})>U(\mu(\mathrm{W})) \rightarrow B(\mathrm{~W})>B(\mu(\mathrm{W})) \\
U(\mathrm{~W})<U(\mu(\mathrm{W})) \rightarrow B(\mathrm{~W})<B(\mu(\mathrm{W})) \\
p(B(\mathrm{~W}), \mathrm{B}(\mu(\mathrm{W}))<\alpha
\end{gathered}
$$

Whereas: $\mathrm{W}$ is a web site, $\mu(\mathrm{W})$ is its modified version; $U(\mathrm{~W})$ and $U(\mu(\mathrm{W}))$ are the usability respectively of the web site and its modified version; $B(\mathrm{~W})$ and $B(\mu(\mathrm{W}))$ are the variations of brand values perception induced by the exposure respectively to the original web site and its modified version; $p$ is the significance level on the increment or decrement of brand value perception $B$ w.r.t. to a statistically critical value $\alpha$. 


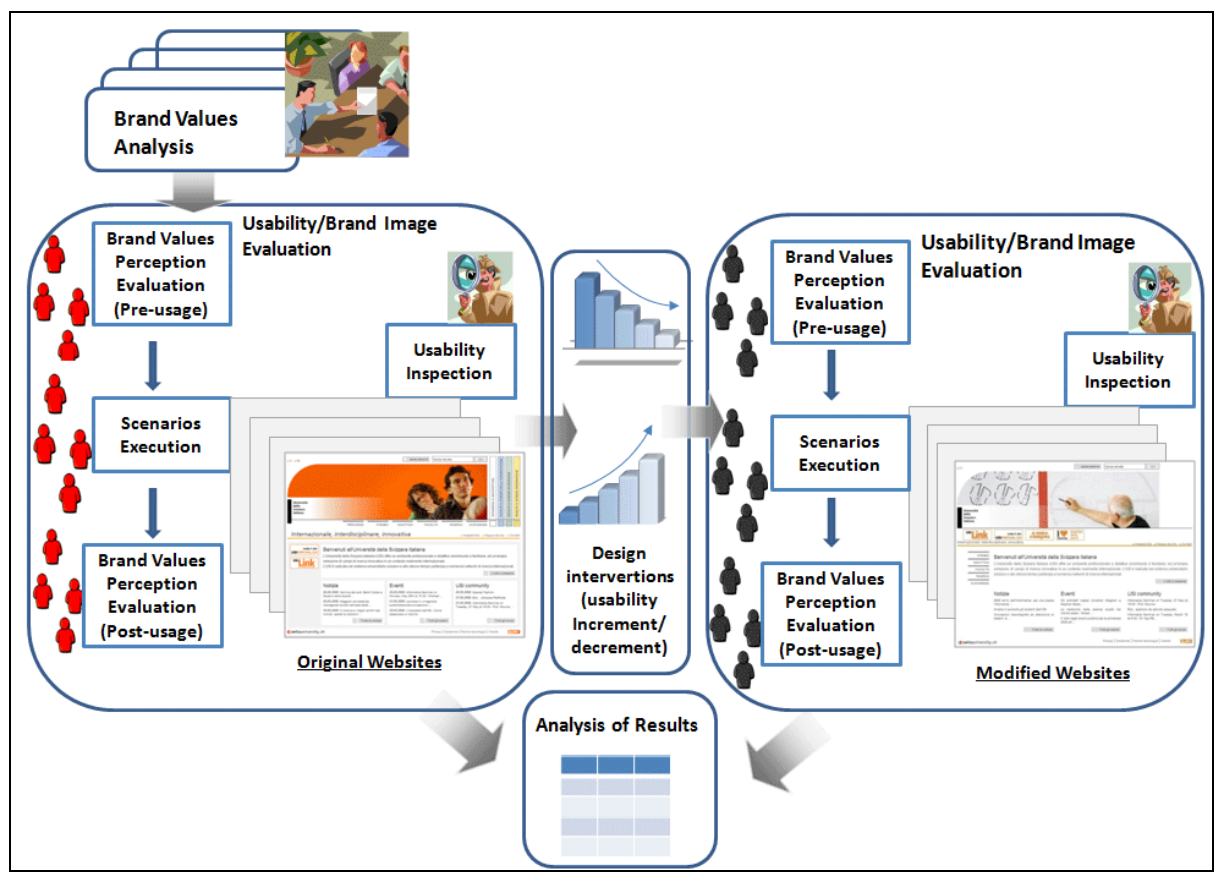

Fig. 1. Synopsis of the experimental flow used in the study

In the following subsection, we illustrate in detail the steps and the instruments of the experimental method put in place and replicated on four different websites, in order to ensure repeatability for future studies.

\subsection{Instruments}

Four websites (see Table 1) were selected randomly among a pool of pre-selected 100 websites - from different domains - meeting the criteria of being informationintensive (offering an articulate and rich set of content and services) and brandintensive (designed as the intended reification on the web of the brand image of a consolidated company or institution).

For each website, two subject groups (each one composed by randomly selected subjects corresponding to the profile of potential user of the website) were recruited for the study and randomly assigned to either the original version of the website or the version with better or worse usability. Only persons who never used the website under study were screened.

Table 1 also shows the distribution of the subject groups across the four websites. Starting from the initial research on the first website (with 5 users), we progressively increased the number of participants in our studies, to provide more substantial evidence for the initial findings and corroborate the study framework. Overall, from March to June 2008 we involved a total of 120 users, distributed in 8 experimental groups. 
Table 1. The web sites considered in our study

\begin{tabular}{|l|l|l|l|c|c|}
\hline \multicolumn{1}{|c|}{ Website } & \multicolumn{1}{|c|}{ URL } & \multicolumn{1}{|c|}{ Sector } & Code & $\begin{array}{c}\text { Sample size } \\
\text { (original } \\
\text { version) }\end{array}$ & $\begin{array}{c}\text { Sample size } \\
\text { (modified } \\
\text { version) }\end{array}$ \\
\hline $\begin{array}{l}\text { University of } \\
\text { Lugano } \\
\text { (Switzerland) }\end{array}$ & www.unisi.ch & $\begin{array}{l}\text { Higher } \\
\text { education }\end{array}$ & USI & 5 & 5 \\
\hline Ryanair Italy & www.ryanair.it & travel & RYANAIR & 15 & 15 \\
\hline Disney Italy & www.disney.it & entertainment & DISNEY & 25 & 25 \\
\hline $\begin{array}{l}\text { Municipal IV } \\
\begin{array}{l}\text { Circle of } \\
\text { Verbania } \\
\text { (Italy) }\end{array}\end{array}$ & www.quartocir & $\begin{array}{l}\text { cultural } \\
\text { center/ } \\
\text { education }\end{array}$ & VERBANIA & 15 & 15 \\
\hline
\end{tabular}

\subsection{Eliciting Brand Values and Salient Scenarios}

We carried on a detailed analysis of the brand values of the entities behind each considered web site to determine the key messages the website is supposed to communicate to its various target audiences. The core question underlying this investigation is to gather traits or attributes describing the brand from the perspective of the company or institution and in relationship to the characteristics of their "customers": how would an entity want to be perceived by its target audience?

We followed the conceptual guidance provided by the value-driven requirements elicitation method illustrated in our previous work [3][4]. According to this method, brand value elicitation is a combination of business analysis, techno-organizational analysis, and user analysis. In our study, this activity was carried out through complementary value-based requirements elicitation techniques, namely: (1) background research and value extraction from explicitly declared brand image sources (institutional mission statements, press releases and investor relations public domain information); (2) semi-structured interviews (via phone or face-to-face) to both institutional stakeholders of a web site (e.g., the university Dean and Students Recruitment Manager in USI) and the "customers" of the entity underneath it (e.g., USI students).

The qualitative data collected with these instruments were consolidated and distilled in a list of (ten, on average) brand values for each website that were further validated with institutional stakeholders. Syntactically, a brand value takes the form of single statements defining a trait of the brand, as shown in Table 2.

Table 2. Excerpt from Brand Values (BV) List of RYANAIR

\begin{tabular}{|c|c|c|c|c|c|c|c|c|}
\hline Ryanair & BV1 & BV2 & BV3 & BV4 & BV5 & BV6 & BV7 & BV8 \\
\hline & Economic & Easy & Trustworthy & Safe & Credible & Growing & Competitive & Flexible \\
\hline
\end{tabular}

During this preliminary phase, we also identified an articulated profile of the main target users for each web site, including their information and operational needs, the motivations for using the application, and the context in which it is intended to be used. We exploited this knowledge to define a set of activity scenarios to be assigned to the users during the experiment. These scenarios capture important, high-priority web tasks for the user, well aligned with the overall mission of the application (e.g. planning a trip on an airline website, rather than looking for the curriculum in a 
given area on a university web site). Scenarios were custom for each system under study, and were designed to have the users explore and be exposed to the most salient content, service and interaction features offered, so that they could have a realistic experience of the web site as it would be in a spontaneous, "normal" condition.

\subsection{Evaluating Usability}

The level of usability for the original and modified websites was obtained by applying a usability inspection process based on heuristics evaluation. In particular, we adopted the MILE+ method [5], which is the latest of a set of conceptual tools for systematic usability inspection we originally developed for hypermedia and contentrich interactive applications [6], and leverages common practices in web usability engineering.

The inspection protocol of MILE+ offers a built-in library of heuristics, coupled with a set of operational guidelines that identify the inspection tasks that must be undertaken by usability experts. These heuristics decompose the general concept of usability into more measurable attributes, each one addressing a different web design dimensions: navigation (heuristics addressing the usability of the information architecture and navigation mechanisms), content (heuristics addressing the general quality of the information offered to the user), layout (heuristics addressing the semiotics of the interface and its graphical look), and technology/performance (heuristics addressing usability issues caused by technological defects).

Each website (both for the original and modified version) has been assigned a team of 3 inspectors, who have individually carried out a systematic heuristics evaluation based on MILE+. Each inspector gave a 1-5 score (level of compliance) to each of the MILE+ heuristics which were found to be applicable to the website under analysis. Then, as in conventional usability inspection, they came together to share and discuss the usability problems found and their severity, consolidate the results and finally converge their scores to an agreed level. At this point, the average heuristics score was calculated and was used as a final single measure for the usability of the website. The same evaluation procedure (using the same team of inspectors) was followed for the modified website. This evaluation enabled to have an overall consistent measure for the usability of website for the original version and for the modified version.

\subsection{Treatment: Altering Usability with Design Interventions}

We improved the usability of the 2 web sites (RYANAIR, VERBANIA) characterized by a low level of usability, and we intervened on the 2 websites (USI, DISNEY) that had a good or very good level of usability, to worsen them. In both cases, the actual content and services remained invariant. Examples are shown in Figure 2. The type of design changes on the original version was kept identical across each couple of applications under analysis. In particular, usability worsening involved the following changes: (a) Navigation usability: from 4 to 8 links relevant to the task scenarios at hand were removed or misplaced in the information architecture; (b) Layout usability: the layout template of the main pages relevant to task scenarios was twisted to lose perfect visual balance, and infringe expected prominence of the main menus; from 4 to 8 link labels relevant to the task scenarios at hand were made more obscure or more 


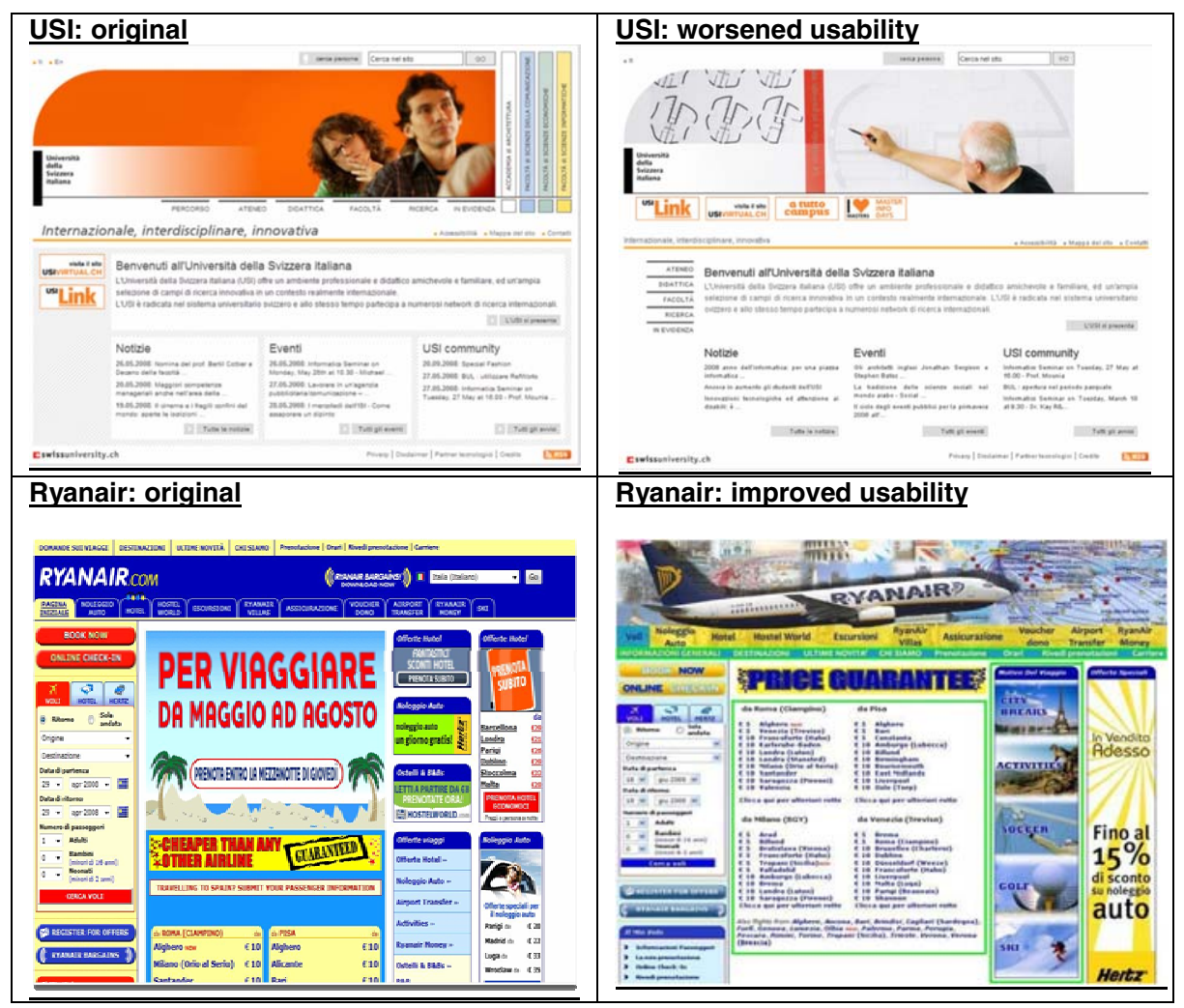

Fig. 2. Homepages of 2 of the original and modified websites. Whereas for Ryanair the changes are visible from the screenshot, for USI the changes included moving the main horizontal main navigation as a left-side bar, moving and increasing the number of mini banners from the left side to the top horizontal bar, and removing clear spacers between the content boxes of the homepage content.

vague in meaning; (d) Content usability: content readability was worsened by removing spacing between the paragraphs and font size in text-intensive pages relevant to the task scenarios.

In case of design interventions aimed at improving the degree of usability, similar types of design interventions described above were applied, but in the opposite direction: giving better prominence to key links, clarifying labels, providing more visual balance and layout order, and improving the readability of the text.

\subsection{Evaluating Brand Values Perception}

To evaluate how the intensity of brand values perception is affected by the exposure to a web site, or its altered version, we proceeded as summarized below:

1. Assessing pre-usage brand values perception: a questionnaire (paper-based) was administrated to the users at the beginning of the evaluation (before using 
the website). We ask them to express their level of agreement with the brand values statements associated to the brand (resulted from the elicitation activity described in 3.4). The aim of this assessment is to establish a starting level of brand values awareness. Since all users recruited never used the website under study, brand values perception captured at this stage derives from previous experience with any reifications of the brand but the website, e.g., traditional advertising, word of mouth, or from positive or negative preconceptions. The set of questions were articulated around a precise investigation focus: how much does Brand $X$ inspire you Value $Y$ ? This was applied to each brand value elicited and the measurement was collected through a likert scale, indicating perception intensity (0: not perceived, 5: strongly perceived).

2. Performing salient scenarios on the website: after the pre-usage questionnaire, each subject was asked to use the website by following 3 assigned scenarios defined in the preliminary phase of user analysis. The average duration of a session of use was approximately 40 minutes.

3. Assessing post-usage brand values perception: right after the execution of the scenarios, the same questionnaire used in 1) was administrated to the users, with the aim of collecting their actual perception of the brand values after the experience with the website, i.e., the short-term "habit change" in brand awareness due to the exposition to the website.

\section{Results}

The preliminary result is that there is a statistically significant difference $(\mathrm{p}<0.01)$ between the brand values perception before and after the use of the websites. This was calculated by running a pair t-test for the results of the pre- and post-usage questionnaires for all the experimental conditions. This shows that the exposition to the website indeed modifies a short-term perception of the brand image.

As to the core of our study, our hypothesis states that there is a significant difference in brand values perception as the usability of the website varies. A paired t-test on the brand values perception of the experimental and the control groups also shows that the actual difference in perception is statistically significant $(\mathrm{p}<0,01$, see Table 3$)$.

As highlighted also in Figure 3, our data indicate that subjects who used a website with more (resp., less) usability problems tend to express a consistently less (resp. more) positive perception of the brand values, with respect to the subjects who used a

Table 3. Usability and Brand Values Perception variation in the 4 experiments

\begin{tabular}{|l|l|l|l|l|l|l|l|l|l|}
\hline & \multicolumn{2}{|c|}{ Usability } & \multicolumn{5}{c|}{ Variation in Brand Values Perception } \\
\hline & original & modified & original & modified & variation & $\begin{array}{c}\text { sample } \\
\text { size }\end{array}$ & $\begin{array}{c}T \\
\text { Signif. } \\
\text { level }\end{array}$ \\
\hline USI & 3,93 & 2,70 & 0,64 & $-1,480$ & 2.12 & 5 & 6,0204 & 0,0003 \\
\hline RYANAIR & 2,86 & 3,51 & $-0,396$ & 0,204 & 0.6 & 15 & 3,5507 & 0,0014 \\
\hline DISNEY & 4,07 & 2,80 & $-0,111$ & $-0,878$ & 0.767 & 25 & 4,4904 & 0,00004 \\
\hline VERBANIA & 2,43 & 3,49 & $-0,57$ & 0,514 & 1.084 & 15 & 3,6988 & 0,0009 \\
\hline
\end{tabular}




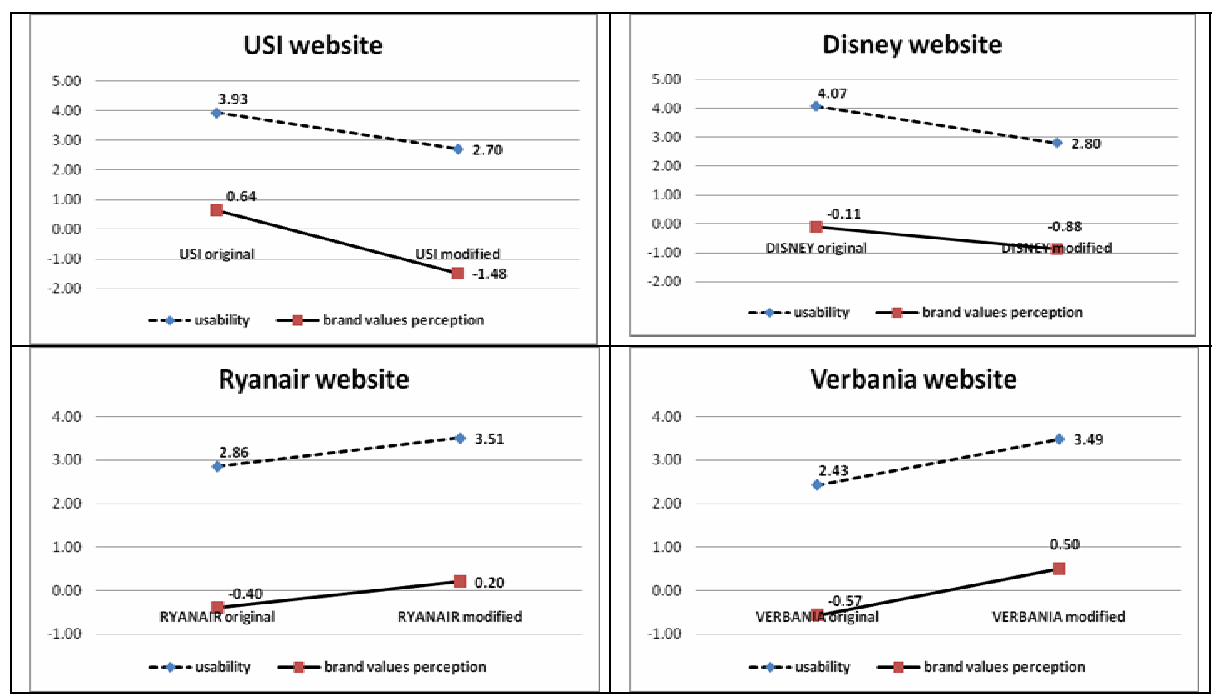

Fig. 3. Results synopsis for the four website experiments. Data points represent the 2 versions of the websites: original and modified with respect to the usability level.

version of the same website featuring fewer (resp. more) usability breakdowns. In other words, the results from all four controlled experiments seem to confirm our research hypothesis: as the usability of a website improves, the level of brand value perception raises, while when usability is worsened, the brand values perception decreases significantly.

\section{Discussion and Conclusions}

Even though the results of this research were partially predictable, to our knowledge this is the first public study that provides some empirical evidence on the correlation between brand perception and web usability. Our research indicates that, in the four experiments, web usability significantly affects brand image, and this influence tends to suggest a positive correlation: the better usability, the better would be the perception of the brand image; the worse is the usability, the more negative would be the users' perception of the brand. Our work considered a specific category of applications, i.e., content intensive branded web sites. It is an open issue for research whether our methodological hypothesis also holds in other categories of branded web applications, which have limited amount of information or services and are almost exclusively designed to convey brand messages by engaging the user emotionally, e.g., thorough impressive visual effects, animations, or videos. We may expect that in web sites of this kind the degree of usability can have a less significant influence on brand perception than other factors related to aesthetics, attractiveness, and emotional design. [10][1][29][32].

Our research has its shortcomings, most notably the relatively limited sample size in each experimental condition. Still, the fact that we have tested our hypothesis in 
four controlled experiments designed according to the same methodological framework, partially compensates this drawback and strengthens the validity of our results. As also pinpointed by Greenberg \& Buxton in their recent paper [20], “... rigorous science also demands replication, since the scientific method advocates for repeated attempts of refuting the hypothesis. ... The more the test tries to refute the hypothesis, the more powerful it is. ...If the hypothesis holds in spite of attempts to refute it, there is more validity in its claims".

This study has also contributed methodologically, in several aspects. While using controlled experiments, scenario-based evaluation, and questionnaire-based data collection are obviously not new, the idea of focusing the overall process on the concept of brand value is original. Existing value-driven approaches normally address two main issues: how to design technology that accounts for human values [14] or creates value for the user "in the world" [8], and how to evaluate how a system meets these requirements [7]. In contrast, we shift the value-oriented perspective to the consideration of the users' perception of the qualities of the entity behind a system, i.e., the brand values. Users may or may not share these values, nor find them worthwhile; still, in a branding strategy it is important to evaluate whether or not (and at which degree) these brand values are perceived. In other words, differently from other valueoriented approaches, our focus is on how a system communicates these values, how the users become aware of and associate them to the image of that entity in their mind, and how usability plays a role in this articulate communication process.

In addition, the general evaluation method that has been adopted in all our four controlled experiments is founded on some novel aspects. Firstly, we operazionalize more rigorously the concept of brand, as usually intended by people in marketing or design, in order to make it measurable. Secondly, we systematically combine the evaluation of brand values perception and usability with a method for systematic elicitation of brand values [3][4][43]. The integration of these methodological components provides a comprehensive conceptual framework that can be reused in other experimental settings, either for replicating our study, or for designing similar studies focusing on the correlation of web branding vs. design factors other than traditional usability. Future researchers can employ or build upon it, saving time and effort.

We have showed that in content intensive web sites, usability as a whole has an impact on the positive or negative perception of brand values. Still, the individual contribution of each different attributes of usability (e.g., usability of information architecture, content, or layout), and of other aspects of interface design (e.g., attractiveness or aesthetics) [9][10][21] to the effective communication or miscommunication of the brand values is to be further explored. What is the role that each of these elements plays to influence the effectiveness of brand values communication? Our study provides initial results and methodological guidelines that future research can refine, either to analytically distill the usability dimensions that bear most of the responsibility in this process, or to prove the actual impact of other design factors. As a final note, it is important to acknowledge that we have considered the influence of usability on the short-term "perception" of brand values, as induced by the web exposure. Studying sustained, long-term brand values perception would be a promising follow-up for this line of work. 


\section{References}

1. Alben, L.: Quality of Experience. Interactions 13(5), 12-15 (1996)

2. Baty, S.: Brand Experience in User Experience Design, http: / / www. uxmatters.com

3. Bolchini, D., Garzotto, F., Paolini, P.: Branding and Communication Goals for ContentIntensive Interactive Applications. In: Proceedings of 15th IEEE International Conference on Requirements Engineering, New Dehli (India), pp. 173-182. IEEE Press, Los Alamitos (2007)

4. Bolchini, D., Garzotto, F., Paolini, P.: Value-Driven Design for "Infosuasive" Web Applications. In: Proceedings of 17th International World Wide Web Conference - WWW 2008, Beijing, China (2008)

5. Bolchini, D., Garzotto, F.: Quality and Potential for Adoption of Web Usability Evaluation Methods: An Empirical Study on MILE+. Journal of Web Engineering 7(4), 299-317 (2008)

6. Costabile, F., Garzotto, F., Matera, M., Paolini, P.: The SUE Inspection: A Systematic and Effective Method for Usability Evaluation of Hypermedia. IEEE Trans. on Systems, Man, and Cybernetics, Part A 32(1), 93-103 (2002)

7. Cockton, G.: A Development Framework for Value-Centered Design. In: Proc. CHI 2003, pp. 1292-1295. ACM Press, New York (2003)

8. Cockton, G.: From quality in use to value in the world. In: CHI 2004 Extended Abstracts. ACM Press, New York (2004)

9. De Angeli, A., Sutcliffe, A., Hartmann, J.: Interaction, usability and aesthetics: what influences users' preferences? In: Proc. 6th Conf. on Designing Interactive Systems, pp. 271 280. ACM Press, New York (2006)

10. De Angeli, A., Lynch, P., Johnson, G.I.: Pleasure versus efficiency in user interfaces: Towards an involvement framework. In: Green, W.S., Jordan, P.W. (eds.) Pleasure with products: Beyond usability, pp. 97-111. Taylor \& Francis, Abington (2002)

11. Fogg, J.B., Soohoo, C., Danielson, D.R., Marable, L., Stanford, J., Tauber, E.R.: How do users evaluate the credibility of Web sites? A study with over 2,500 participants. In: Proc. Designing For User Experiences 2003, pp. 1-15. ACM Press, New York (2003)

12. Fogg, B.J., et al.: What Makes Web Sites Credible? A Report on a Large Quantitative Study. In: Proc. CHI 2001, pp. 61-68. ACM Press, New York (2001)

13. Fogg, B.J.: Persuasive Technology. Morgan Kaufmann, San Francisco (2003)

14. Friedman, B., Kahn, P.H.: Human values, ethics, and design. In: Jacko, J.A., Sears, A. (eds.) The human computer interaction handbook. Lawrence Erlbaum Associates, Mahwah (2003)

15. Friedman, B., Kahn, P.H., Howe Jr., D.C.: Trust online. Comm. of the ACM 43(12), 3440 (2000)

16. Gerstman, R. (ed.): Branding@ thedigitalage. Palgrave (2001)

17. Gilbert, A.C., Iacobucci, D.: Marketing Research: Methodological Foundations, 9th edn. Thomson South-Western Publishers (2005)

18. Gobé, M.: Emotional Branding. Allworth Press (2001)

19. Gordijn, J., Yu, E., Raadt, B.: E-Service Design Using i* and e3value Modeling. IEEE Software 23(5), 26-33 (2006)

20. Greenberg, S., Buxton, B.: Usability Evaluation Considered Harmful (Some of the Time). In: Proc. CHI 2008, pp. 111-120. ACM Press, New York (2008)

21. Hartmann, J., Sutcliffe, A., De Angeli, A.: Investigating attractiveness in web user interfaces. In: Proc. CHI 2007, pp. 387-396. ACM Press, New York (2007) 
22. Hassenzahl, M.: The interplay of beauty, goodness and usability in interactive products. Human-Computer Interaction 19(4), 319-349 (2004)

23. Jokela, T.: When good things happen to bad products: where are the benefits of usability in the consumer appliance market? Interactions 11(6), 28-35 (2004)

24. Keinonen, T.: One-dimensional usability - Influence of usability on consumers' product preference. University of Art and Design Helsinki, - doctoral dissertation (1998)

25. Kim, J., Lee, J., Choi, D.: Designing Emotionally Evocative Homepages: An Empirical Study of the Quantitative Relations Between Design Factors and Emotional Dimensions. Int. J. of Human-Computer Studies 59(6), 899-940 (2003)

26. Knemeyer, D.: Brand Experience and the Web. Digital Web Magazine, http: //www.digital-web.com/articles/ brand_experience_and_the_web/

27. Lavie, T., Tractinsky, N.: Assessing dimensions of perceived visual aesthetics of websites. International Journal of Human-Computer Studies 60(3), 269-298 (2004)

28. Marcus, A.: Branding 101. Interactions 11(5), 14-21 (2004)

29. McNamara, N., Kirakowski, J.: Defining Usability: Quality of Use or Quality of Experience? In: Proc. 2005 IEEE Int. Professional Communication Conf., pp. 200-2004. IEEE Press, Los Alamitos (2005)

30. Muller, B., Chandon, J.L.: The Impact of Visiting a Brand Website on Brand Personality. Electronic Markets 13(3), 210-221 (2003)

31. Nolan, K.: Europe Brand Perception: Nokia Dominates for Loyalty and Aspiration. Strategic Analytics Report Overview, http: / /www. strategyanalytics.com/

32. Norman, D.A.: Emotional Design. Basic Books (2004)

33. Park, S., Harada, A., Igarashi, H.: Influences of Product Preferences on Product Usability. In: Proc. CHI 2006, pp. 87-92. ACM Press, New York (2006)

34. Rondeau, D.: For Mobile Applications, Branding is Experience. Comm. of the ACM 48(7), 61-66 (2005)

35. Sealey, P.: How E-commerce Will Trump Brand Management. Harvard Business Review 68(4) (1999)

36. Sinha, I.: Cost Transparency: The Net's Real Threat to Prices and Brands. Harvard Business Review 78(2), 43-50 (2000)

37. Spool, J.: Determining How Design Affects Branding, http: / / www.uie.com/articles/design_and_branding /

38. Spool, J.M.: Branding and usability, http: / /www.uie.com/articles/branding_usability/

39. Tractinsky, N.: Aesthetics and apparent usability: Empirically assessing cultural and methodological issues. In: CHI 1997 Electronic Publications. ACM, New York (1997), http://sigchi.org/chi97/proceedings/paper/nt.htm

40. Tractinsky, N., Shoval-Katz, A., Ikar, D.: What is beautiful is usable. Interacting with Computers 13(2), 127-145 (2000)

41. Wheeler, A.: Brand Identity: A Complete Guide to Creating, Building, and Maintaining Strong Brands. Wiley, Chichester (2006)

42. Young \& Rubricam Consulting. Brand Asset Evaluator Survey, http://www.12manage.com/methods_brand_asset_valuator.html

43. Bolchini, D., Garzotto, F.: Design Requirements for Communication-Intensive Interactive Applications. In: Lyttinen, C., Loucopoulos, P., Mylopoulos, J., Robinson, W. (eds.) Design Requirements Engineering: A Ten-Year Perspective, February 2009. Lecture Notes Series in Business Information Processing, pp. 408-431. Springer, Heidelberg (2009) 